\title{
Application and Study on Relationship Between Relative Permeability Ratio and Water Saturation Curve
}

\author{
Li Jun ${ }^{1,3, ~ *, ~ K a n g ~ K a i ~}{ }^{1}$, Peng Xiaodong ${ }^{2}$, Lu Yan ${ }^{2}$, Jiang Lifu ${ }^{1}$ \\ ${ }^{1}$ CNOOC Ltd. Tianjin, Tianjin, China \\ ${ }^{2}$ CNOOC Ltd. Zhanjiang, Zhanjiang, Guangdong, China \\ ${ }^{3}$ Engaged in Reservoir Engineering and Reserve Evaluation, CNOOC Ltd. Tianjin, Tianjin, China

\section{Email address:} \\ lijun54@cnooc.com.cn (Li Jun), kangkai@cnooc.com.cn (Kang Kai), pengxd@cnooc.com.cn (Peng Xiaodong), \\ luyan15@cnooc.com.cn (Lu Yan),jianglf2@cnooc.com.cn (Jiang Lifu) \\ ${ }^{*}$ Corresponding author
}

\section{To cite this article:}

Li Jun, Kang Kai, Peng Xiaodong, Lu Yan, Jiang Lifu. Application and Study on Relationship Between Relative Permeability Ratio and Water Saturation Curve. International Journal of Oil, Gas and Coal Engineering. Vol. 4, No. 3, 2016, pp. 24-29. doi: 10.11648/j.ogce.20160403.11

Received: March 29, 2016; Accepted: June 22, 2016; Published: June 28, 2016

\begin{abstract}
In the process of oil field development, the law of water cut is usually described by exponent model, but during the early water breakthrough stage and ultra-high water cut stage, relative permeability ratio of oil to water $\left(K_{r o} / K_{r w}\right)$ and water saturation $\left(S_{w}\right)$ is no longer linear relations in semilog coordinate, so it has an important influence on water cut increasing rate, theoretical production index, oil displacement efficiency, relationship between recovery and water cut etc. Based on relation curve character of relative permeability ratio of oil to water $\left(K_{r o} / K_{r w}\right)$ and water saturation $\left(S_{w}\right)$, this paper proposes a new function model in order to reduce prediction error, such as production index and water cut increasing rate. According to nonlinear properties of the model, Newton algorithm is supposed to be used for optimization solution. Finally, take relative permeability data of P Oilfield as an example to testify, and results show that fitting precision of the model is quite high and it possess nicer applicability. On this basis, the relationship between water cut and recovery, relationship between water cut increasing rate and recovery are derived. By comparing water cut and water cut increasing rate with recovery degree, it can be used to guide the development as the foundation of geology and reservoir of P Oilfield.
\end{abstract}

Keywords: Relative Permeability Ratio, Water Saturation, Optimization Solution, Newton Algorithm

\section{Introduction}

Evaluate water production law of oil production well is a key point in oilfield development. The precision of water cut forecast will affect reservoir engineer's right decision. Water cut percentage $f_{w}$ is a significant evaluation parameter to describe water production law, without considering the influence of gravity and capillary pressure, according to the flow equation, it is calculated as follows:

$$
f_{w} \frac{Q_{w}}{Q_{w} Q_{o}} \frac{1}{1 \frac{K_{r o}}{K_{r w}} \frac{w}{o}}
$$

The water cut percentage $f_{w}$ of ground which is converted by volume coefficient is calculated as follows:

$$
f_{w} \frac{Q_{w}}{Q_{w} Q_{o}} \frac{1}{1 \frac{K_{r o}}{K_{r w}} \frac{{ }_{w} B_{w}}{B_{o}}}
$$

Equation (2) shows that viscosity ratio of oil to water can be considered as a constant value for a specific reservoir, so relative permeability ratio determination is important to water cut. How to define functional relation between $K_{r o} / K_{r w}$ and $S_{w}$ will decide forecast precision of water cut in oilfield development.

\section{Exponent Model Establishment}

In semi-log coordinate relation curve of $K_{r o} / K_{r w}$ and $S_{w}$ has 
two curved ends and one straight line in the middle [1-15], which can be illustrated in Figure 1. Select the middle straight line of the curve and calculated by empirical equation (3) [1, 2, 3] below:

$$
\frac{K_{r o}}{K_{r w}} a e^{b S_{w}}
$$

Ren [4] proposed characterizing relationship of and $S_{w}$ by equation (4), established a new method to describe the various forms of water flooding curve with equation; Miao and Liu [5] et al. characterized 3 kind of the relationship between water cut and recovery as well as the type of water cut increasing rate and recovery; Gao and $\mathrm{Li}[6,7]$ et al. proposed using two straight lines method for data matching separately in medium water cut period and high water cut period, calculated the recoverable reserves of Xingbei development area of Daqing oil field and verified the cumulative oil production and water cut. Song and Bing Shao [8, 9] et al. also made enormous effort on model of $K_{r o} / K_{r w}$ and $S_{w}$, derived a new water flooding characteristic curve which is more applicable for high water-cut oil field by the average water saturation equation which proposed respectively by Buckley-leverett and Welge.

$$
\frac{K_{r o}}{K_{r w}}=a e^{-b S_{w}^{n}}
$$

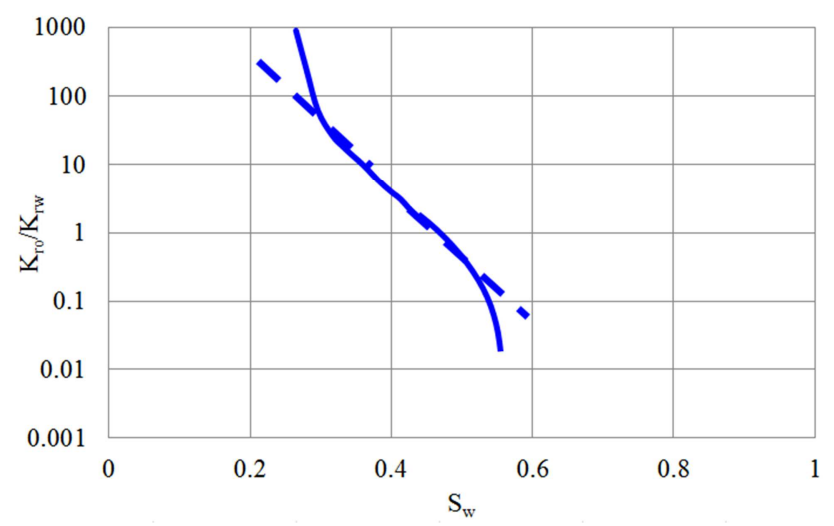

Figure 1. Relation curve of relative permeability ratio and water saturation.

However the middle straight line can be only applied to medium water cut period, which is not suitable to relative low or high water saturation period. It will reduce accuracy of water production forecast. Two straight lines method take data matching separately in medium water cut stage and high water cut stage into consideration and improved prediction accuracy. But unified functional relation is not defined and it cannot match data in low water saturation period. The expression of power function of relative permeability which define functional relation between $K_{r o} / K_{r w}$ and $S_{w}$ improve the fitting precision, but it could not solve the problem radically. While in actual oilfield production, it is in low or high water saturation period in a long time. So according to the curve characteristic (two curved ends and straight line in the middle), a new exponential model as equation (5) is established to fit relation of $K_{r o} / K_{r w}$ and $S_{w}$ in this paper:

$$
\ln \frac{K_{r o}}{K_{r w}}=a e^{-b S_{w}}-c e^{d S_{w}}
$$

\section{Exponent Model Solution}

Equation (5) has strong nonlinearity, to solving parameters like a, b, c and d, function $F(X)$ is proposed as follows:

$$
F(X)=\sum_{j=1}^{n}\left[\ln \left(\frac{K_{o j}}{K_{w j}}\right)-a e^{-b S_{w j}}+c e^{d S_{w j}}\right]^{2}
$$

Thereinto, $X=(a, b, c, d)$

Apparently $F(X)$ has continuous second-order partial derivative, with positive definite Hesse matrix. Therefore use optimal principle and solving parameters by Newton algorithm [9].

Solution steps are as follows:

(1) Select iteration initial point $X_{0}$, assume $\mathrm{k}=0$; calculate gradient matrix $\nabla F\left(X_{k}\right)$;

(2) Calculate Hesse matrix $\nabla^{2} F\left(X_{k}\right)$ and its inverse matrix $\left[\nabla^{2} F\left(X_{k}\right)\right]^{-1}$;

(3) Calculate $X_{k+1}=X_{k}-\left[\nabla^{2} F\left(X_{k}\right)\right]^{-1} \cdot \nabla F\left(X_{k}\right)$ and $\nabla F\left(X_{k+1}\right)$;

(4) Test whether the condition $\left\|\nabla F\left(X_{k+1}\right)\right\| \leq \varepsilon$ is satisfied: if so, $X_{k+1}$ is optimal solution; otherwise, set $\mathrm{k}=\mathrm{k}+1$ and repeat step (2).

\section{Case Demonstration and Comparison}

Take relative permeability data of $\mathrm{P}$ oilfield as an example, which is illustrated in Table 1 and Figure 2, this paper studied relation between water saturation and relative permeability ratio of the area.

Table 1. Relative permeability data of P oilfield.

\begin{tabular}{lll}
\hline $\mathbf{S}_{\mathbf{w}}$ & $\mathbf{K}_{\mathbf{r w}}$ & $\mathbf{K}_{\mathbf{r o}}$ \\
\hline 0.22 & 0 & 1 \\
0.24 & $1.40 \mathrm{E}-05$ & 0.907 \\
0.259 & 0.00011177 & 0.819 \\
0.279 & 0.00037723 & 0.736 \\
0.299 & 0.00089417 & 0.659 \\
0.318 & 0.00174643 & 0.587 \\
0.338 & 0.00301783 & 0.52 \\
0.357 & 0.00479221 & 0.458 \\
0.377 & 0.00715338 & 0.401 \\
0.397 & 0.01018519 & 0.348 \\
0.416 & 0.01397145 & 0.3 \\
0.436 & 0.018596 & 0.257 \\
0.456 & 0.02414266 & 0.217 \\
0.475 & 0.03069527 & 0.181 \\
0.495 & 0.03833765 & 0.15 \\
0.514 & 0.04715364 & 0.121 \\
\hline
\end{tabular}




\begin{tabular}{lll}
\hline $\mathbf{S}_{\mathbf{w}}$ & $\mathbf{K}_{\mathrm{rw}}$ & $\mathbf{K}_{\mathrm{ro}}$ \\
\hline 0.534 & 0.05722705 & 0.097 \\
0.554 & 0.06864172 & 0.076 \\
0.573 & 0.08148148 & 0.057 \\
0.593 & 0.09583016 & 0.042 \\
0.613 & 0.11177158 & 0.03 \\
0.632 & 0.12938958 & 0.02 \\
0.652 & 0.14876797 & 0.012 \\
0.671 & 0.1699906 & 0.007 \\
0.691 & 0.19314129 & 0.003 \\
0.711 & 0.21830387 & 0.001 \\
0.73 & 0.24556216 & 0 \\
0.75 & 0.275 & 0 \\
\hline
\end{tabular}
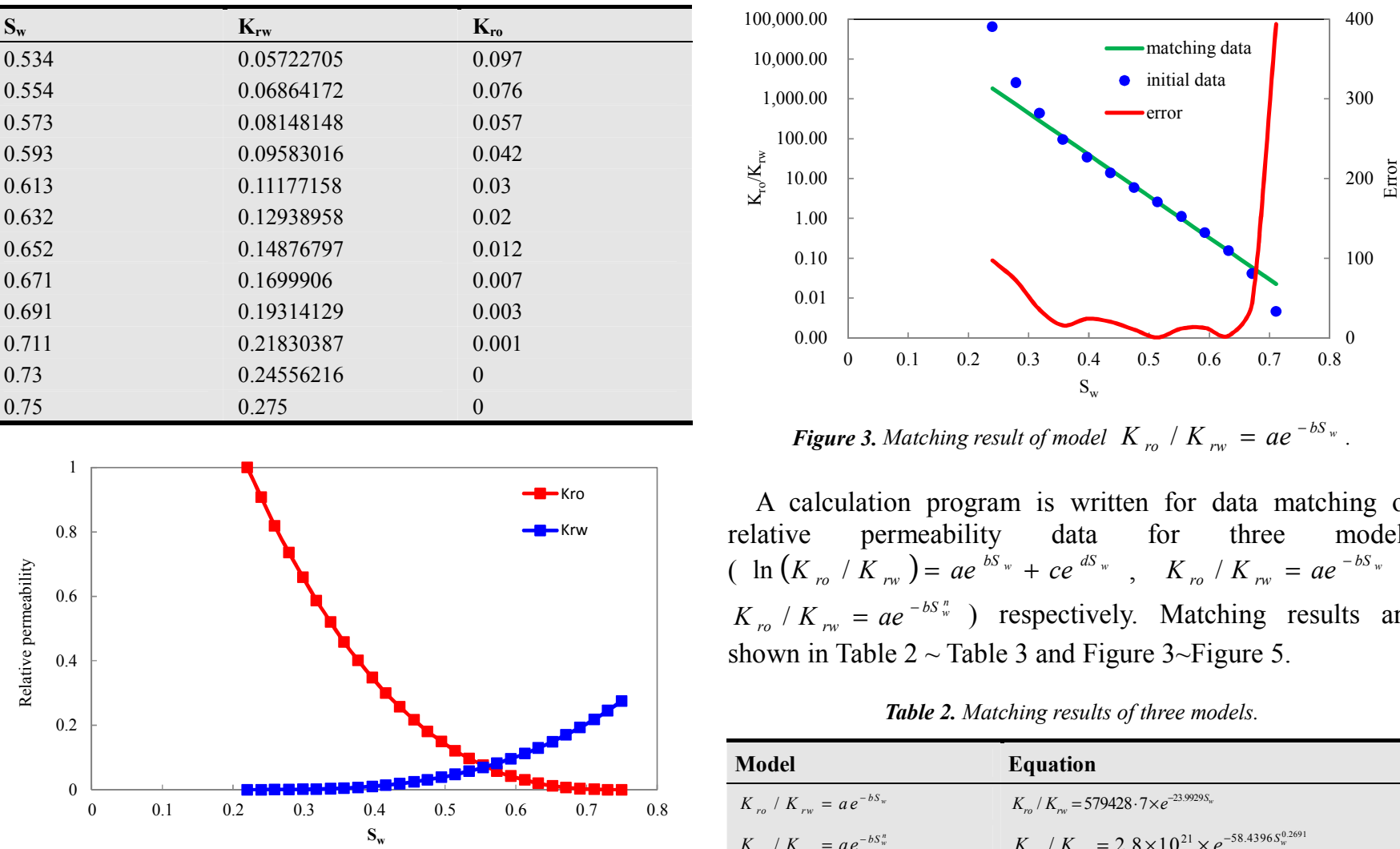

Figure 3. Matching result of model $K_{r o} / K_{r w}=a e^{-b S_{w}}$.

Figure 2. Relative permeability curve of $P$ Oilfield.

A calculation program is written for data matching of relative permeability data for three models $\left(\ln \left(K_{r o} / K_{r w}\right)=a e^{b S_{w}}+c e^{d S_{w}}, K_{r o} / K_{r w}=a e^{-b S_{w}}\right.$, $\left.K_{r o} / K_{r w}=a e^{-b S_{w}^{n}}\right)$ respectively. Matching results are shown in Table $2 \sim$ Table 3 and Figure 3 Figure 5.

Table 2. Matching results of three models.

\begin{tabular}{ll}
\hline Model & Equation \\
\hline$K_{r o} / K_{r w}=a e^{-b S_{w}}$ & $K_{r o} / K_{r w}=579428.7 \times e^{-23.9929 S_{w}}$ \\
$K_{r o} / K_{r w}=a e^{-b S_{w}^{*}}$ & $K_{r o} / K_{r w}=2.8 \times 10^{21} \times e^{-58.4396 S_{w}^{0.2001}}$ \\
$\ln \left(K_{r o} / K_{r w}\right)=a e^{b S_{w}}+c e^{a S_{w}}$ & $\ln \left(K_{r o} / K_{r w}\right)=-0.00292 e^{10.08 s_{w}}+56.01865 e^{-6.838 S_{w}}$ \\
\hline
\end{tabular}

Table 3. Matching results of three models.

\begin{tabular}{|c|c|c|c|c|c|c|c|}
\hline Sw & $\mathbf{K o} / \mathbf{K w}$ & $K_{r o} / K_{r w}=a e^{-b S_{w}}$ & Error (\%) & $K_{r o} / K_{r w}=a e^{-b S_{w}^{n}}$ & Error (\%) & $\ln \left(K_{r o} / K_{r w}\right)=a e^{b S_{w}}+c e^{d S_{w}}$ & Error $(\%)$ \\
\hline 0.24 & 64785.71 & 1829.33 & 97.18 & 1829.33 & 97.18 & 49833.50 & 23.08 \\
\hline 0.28 & 2552.25 & 717.65 & 71.88 & 717.65 & 71.88 & 3850.83 & 50.88 \\
\hline 0.32 & 436.20 & 281.54 & 35.46 & 281.54 & 35.46 & 533.95 & 22.41 \\
\hline 0.36 & 95.58 & 110.45 & 15.56 & 110.45 & 15.56 & 114.98 & 20.30 \\
\hline 0.40 & 34.17 & 42.30 & 23.80 & 42.30 & 23.80 & 33.36 & 2.38 \\
\hline 0.44 & 13.82 & 16.59 & 20.08 & 16.59 & 20.08 & 12.60 & 8.79 \\
\hline 0.48 & 5.90 & 6.51 & 10.40 & 6.51 & 10.40 & 5.53 & 6.22 \\
\hline 0.51 & 2.57 & 2.55 & 0.47 & 2.55 & 0.47 & 2.61 & 1.76 \\
\hline 0.55 & 1.11 & 0.98 & 11.65 & 0.98 & 11.65 & 1.20 & 8.58 \\
\hline 0.59 & 0.44 & 0.38 & 12.44 & 0.38 & 12.44 & 0.51 & 16.44 \\
\hline 0.63 & 0.15 & 0.15 & 2.61 & 0.15 & 2.61 & 0.17 & 12.49 \\
\hline 0.67 & 0.04 & 0.06 & 43.42 & 0.06 & 43.42 & 0.04 & 2.17 \\
\hline 0.71 & 0.00 & 0.02 & 393.79 & 0.02 & 393.79 & 0.00 & 2.27 \\
\hline
\end{tabular}

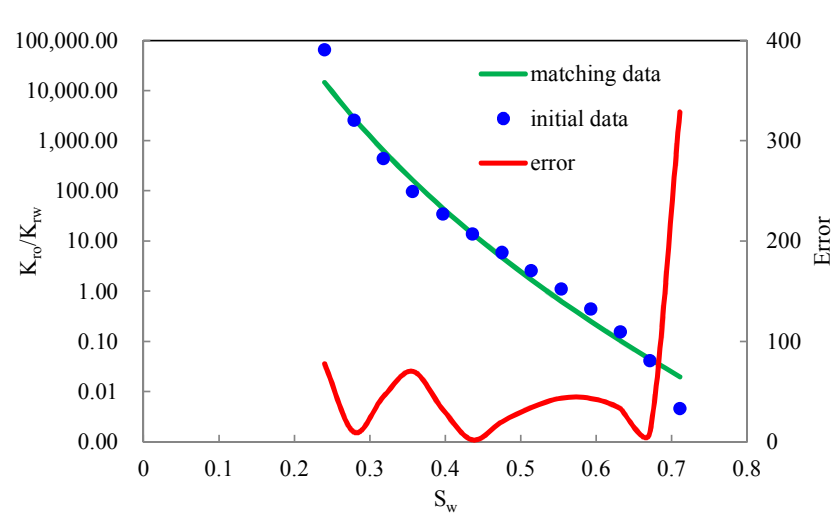

Figure 4. Matching result of model $K_{r o} / K_{r w}=a e^{-b S_{n}^{n}}$.

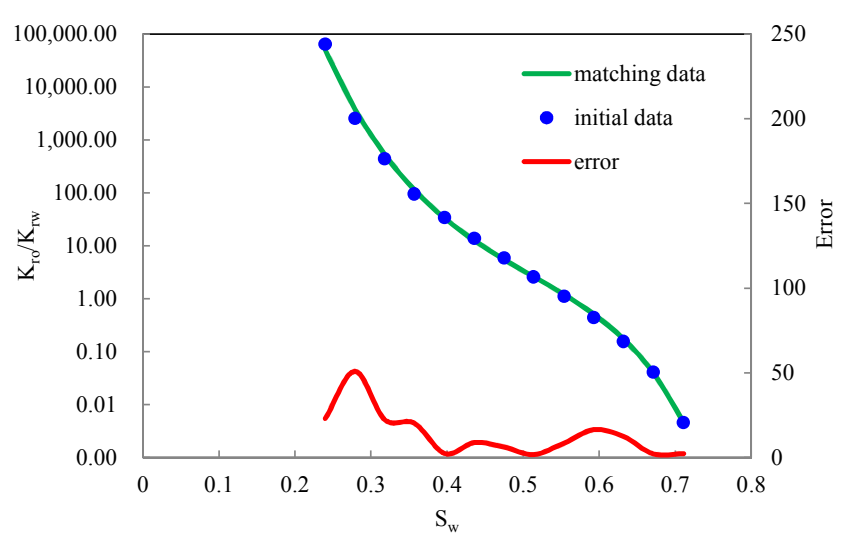

Figure 5. Matching result of model $\ln \left(K_{r o} / K_{r v}\right)=a e^{b S_{w}}+c e^{a S_{w}}$. 
Figure 3 shows that model $K_{o} / K_{w}=a e^{-b S_{w}}$ is suitable to data matching in middle straight line, while fitting accuracy is low in low or high water saturation period. Especially in high water saturation period, the fitting error can reach $394 \%$; Figure 4 indicates that comparing to model $K_{o} / K_{w}=a e^{-b S_{w}}$, fitting accuracy of model $K_{o} / K_{w}=a e^{-b S_{w}^{n}}$ has been improved, but still low; however model $\ln \left(K_{o} / K_{w}\right)=a e^{b S_{w}}+c e^{d S_{w}}$ has higher fitting accuracy and relative lower error. It shows that $\ln \left(K_{o} / K_{w}\right)=a e^{b S_{w}}+c e^{d S_{w}}$ can describe the relationship between relative permeability ratio of oil to water $\left(K_{r o} / K_{r w}\right)$ and water saturation $\left(S_{w}\right)$ more accurately.

\section{Application}

\subsection{Relationship Between Water Cut and Recovery}

According to the fitting result of equation (4), the water cut percentage $f_{w}$ can be calculated as follows:

$$
f_{w}=\frac{1}{1+\frac{\mu_{w} B_{w}}{\mu_{O} B_{o}} e^{a e^{b S_{w}}+c e^{d S_{w}}}}
$$

The relationship between recovery $\left(R_{f}\right)$ and water saturation $\left(S_{w}\right)$ is as follows:

$$
R_{f}=\frac{S_{w}-S_{w i}}{1-S_{w i}-S_{o r}}
$$

In this case, we set $1-S_{w i}-S_{o r}$ to be $\mathrm{A}, S_{w i}$ to be B, equation (7) is converted to equation (8) as follows:

$$
f_{w}=\frac{1}{1+\frac{\mu_{w} B_{w}}{\mu_{o} B_{o}} e^{a e^{b\left(A R_{f}+B\right)}+c e^{d\left(A R_{f}+B\right)}}}
$$

\subsection{Relationship Between Water Cut Increasing Rate and Recovery}

Water cut increasing rate is defined as an increase value of water cut while $1 \%$ OGIP is produced, it is calculated as follows:

$$
f_{w}^{\prime}=\frac{d f_{w}}{d R_{f}}
$$

Water cut increasing rate $\left(f_{w}^{\prime}\right)$ is calculated as follows by formula (9):

$$
\begin{aligned}
& f_{w}^{\prime}=\frac{1}{\left(1+\frac{\mu_{w} B_{w}}{\mu_{o} B_{o}} e^{a e^{b\left(A R_{f}+B\right)}+c e^{d\left(A R_{f}+B\right)}}\right)^{2}} \frac{\mu_{w} B_{w}}{\mu_{o} B_{o}} e^{a e^{b\left(A R_{f}+B\right)}+c e^{d\left(A R_{f}+B\right)}} * \\
& \left(a b A e^{b\left(A R_{f}+B\right)}+c d A e^{d\left(A R_{f}+B\right)}\right)
\end{aligned}
$$

We can plot the relationship between water cut increasing rate $\left(f_{w}^{\prime}\right)$ and recovery $\left(R_{f}\right)$.

\subsection{Case Analysis}

In regional structure, P Oilfield lies in the east of Bohai Bay Basin and northeast end of middle section of Bonan Low bulge, and is developed on Tancheng-Lujiang fault zone. Bonan low bulge is next to Bozhong and Bodong depression in the north, with southwest-southeast surrounded by Yellow River Estuary and Miaoxi depression, hence it refers to one of the most favorable oil-gas enrichment areas in Bohai Sea, and owns superior geological conditions of oil-gas accumulation. Cenozoic and Mesozoic strata are mainly revealed in drilling of Area $1 / 3 / 8 / 9$ of P Oilfield, which falls into Neogene Pingyuan Formation, Minghua Formation, Guantao Formation and Palaeogene Dongying Formation from top down according to lithology, electric characteristics, paleontological analysis and regional stratum comparison. Main Oil Saturation formation develops in Lower Minghua Formation and Guantao Formation of Neogene. Since Neogene, this area enters peneplanation period and forms a set of sedimentary system centered on fluvial facies. Guantao Formation is braided river deposit, and Lower Minghua Formation belongs to meandering stream deposit, with reservoir lithology referring to terrigenous clastic rock of fluvial facies deposit. According to the principle of "cycle comparison, and step control" and in combination with drilling of producing well, stratum thickness, development of oil reservoir and relationship with seismic reflection horizon, Oil Saturation target intervals are divided into 13 oil formations (respectively named as L00, L10, L20, L30, L40, L50, L60, L70, L80, L90, L100, L110 and L120), in which, main Oil Saturation target intervals of Lower Minghua Formation are divided into 5 oil formations (L00-L40 oil formations) and those of Guantao Formation are divided into 8 oil formations (L50-L120 oil formations). L50-L100 oil formations is main oil producing in P Oilfield.

According to the actual oil-water parameters in P Oilfield (Table 4), it can be concluded that the relationship between water cut and recovery degree and water cut increasing rate and recovery degree (Figure 6 Figure 7).

Table 4. Actual oil-water parameters in P Oilfield.

\begin{tabular}{ll}
\hline$\mu_{\mathrm{w}}$ & 0.5 \\
$\mu_{\mathrm{o}}$ & 30 \\
$\mathrm{~B}_{\mathrm{w}}$ & 1 \\
$\mathrm{~B}_{\mathrm{o}}$ & 1.1177 \\
\hline
\end{tabular}

(1) Relationship between water cut and recovery 


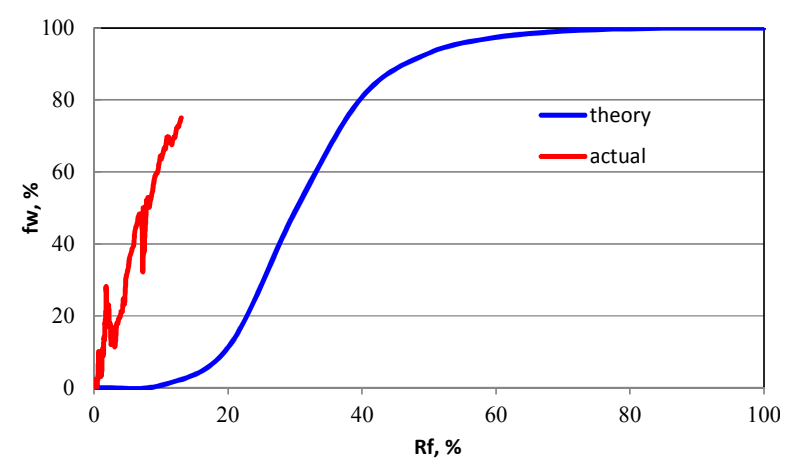

Figure 6. Relationship between water cut and recovery of theory and actual.

Figure 6 shows that the error between actual water cut increasing curve and theoretical curve is bigger. The theoretical water cut rising curve increases as " $\mathrm{S}$ " form, the actual water cut increasing curve increase as the early stage of convex type.

(2) Relationship between water cut increasing rate and recovery

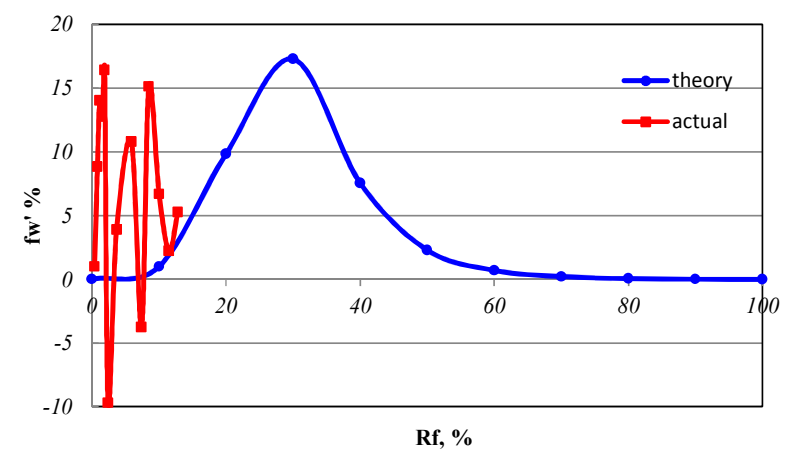

Figure 7. Relationship between water cut increasing rate and recovery of theory and actual.

Figure 7 shows that the error between actual water cut increasing rate curve and theoretical curve is still worse. The theoretical water cut increasing rate curve is usually increased first and decreased then, the actual curve shows a high water cut increasing rate in the early stage, 2008 and 2011, the water cut increasing rate is negative because of the new platform $(\mathrm{B} / \mathrm{C} / \mathrm{D})$ put into operation as well as the oil spill risk lead the oilfield to shut down. At present, the water cut increasing rate of Bohai P Oilfield is 5.3\%.

Figure 6 Figure 7 show that $\mathrm{P}$ Oilfield has the poor development effect. According to the analysis, the main reason include:(1) Large sections with one-set series of strata development and severe interlayer interference. Oil wells mainly produce the Guantao Formation ( 8 oil formations and 35 sub-layers), with a vertical span of the production horizon $300-350 \mathrm{~m}$, average well control $130 \times 10^{4} \mathrm{~m}^{3}$. There is severe interlayer interference in the production process. Moreover, according to the oil well production data, with the increase of production thickness, the production capacity of oil wells shows a downward trend. The interlayer interference coefficient for separate and commingled production of the Upper and Lower Guantao Formation is $40 \%$. The interlayer contradiction in large sections of commingled production is obvious. (2) Imbalanced water absorption of injection wells, with severe breakthrough of injected water. The water injection time in P Oilfield is quite long, and the monolayer breakthrough of injected water becomes more serious. The water absorption profile of water injection wells shows that the imbalance of water absorption in sub-layers causes the imbalance of the produced fluid profile of production wells, as well as the large difference in water cut among all layers and in water flooding effects. According to the problems which affect the development of P Oilfield, we can improve the effect of water flooding by means of profile control and optimization of water injection in short-term, make comprehensive adjustment for long term goal.

\section{Conclusion}

(1) In low or high water saturation period, traditional exponent model presents low prediction accuracy. This paper proposed a new exponent model, which can establish function relation between relative permeability ratio and water saturation in a high accuracy.

(2) According to new model, the relationship between water cut and recovery, relationship between water cut of increasing and recovery are derived.

(3) By comparing the water cut and recovery degree, water cut increasing rate and recovery degree, it can be seen that the development of P Oilfield is poor. At the same time, this paper puts forward some corresponding measures and suggestions.

\section{References}

[1] He G. S., "Petrophysics", Beijing: Petroleum Industry Press, November 1994.

[2] Wang Y. C., Xiang Y., Deng L. Z., "Petrophysics", Chengdu: Sichuan Publishing House of Science \& Technology, August 2006.

[3] Jiang M., Song F. X., Wu X. C., "Building and application of a mathematical model for water cut and time relationship", Petroleum Exploration and Development, 1999, 26, (1), pp. 65-67.

[4] Ren Y. L., "A new generalized water drive curve", Xinjiang Petroleum Geology, 2006, 27, (2), pp. 188-190.

[5] Miao F. f., Liu X. h., "Comprehensive Research and Practice of Law of Water Cut Rise of Water Flooding Oilfield", Journal of Chongqing University of Science and Technology (Natural Sciences Edition), 2014, 16 (2): 71-73

[6] Gao Li, Song K. P., Ma C. H., "Two straight lines to forecast development index of high water-cut oilfield", Petroleum Drilling Techniques, 2008, 36, (5), pp. 72-74.

[7] Li L. L., Song K. P., Gao L., "Water flooding behavior of high water-cut oilfield", Petroleum Drilling Techniques, 2009, 37, (3), pp. 91-94.

[8] Song Z. J., Li Z. P., Lai F. P., et al, "Derivation of water flooding characteristic curve for high water-cut oilfields", Petroleum Exploration and Development, 2013, 40, (2), pp. 201-207. 
[9] Bing S. X., "Study on relative permeability equation adapted at ultra-high water-cut stage", Journal of Oil and Gas Technology, 2012, 34, (10), pp. 118-120.

[10] Guo K., Chen L., Wei Y. H., "Optimization and application”, Higher Education Press, 2007, pp. 75-76.

[11] H. Mulyadi, R. Amin, A. F. Kennaird, (2001 Oct), "Practical Approach To Determine Residual Gas Saturation and Gas-Water Relative Permeability", Presented at the 2001 SPE Annual Technical Conference.

[12] M Oostrom, RJ Lenhard, "Comparison of relative permeability-saturation-pressure parametric models for infiltration and redistribution of a light nonaqueous-phase liquid in sandy porous media", Advances in Water Resources, 1998, 21 (2): 145-157.

[13] AA Hamouda, O Karoussi, EA Chukwudeme, "Relative permeability as a function of temperature, initial water saturation and flooding fluid compositions for modified oil-wet chalk", Journal of Petroleum Science \& Engineering, 2008, 63 (1-4): 61-72.

[14] VH Nguyen, AP Sheppard, MA Knackstedt, WV Pinczewski, "The effect of displacement rate on imbibition relative permeability and residual saturation", Journal of Petroleum Science \& Engineering, 2006, 52 (1-4): 54-70.

[15] J Liu, F Agostini, F Skoczylas, "From relative gas permeability to in situ saturation measurements", Construction \& Building Materials, 2013, 40 (40): 882-890.

[16] Y Shi, S Cheng, S Quan, "Fractal-based theoretical model on saturation and relative permeability in the gas diffusion layer of polymer electrolyte membrane fuel cells", Journal of Power Sources, 2012, 209 (209): 130-140. 